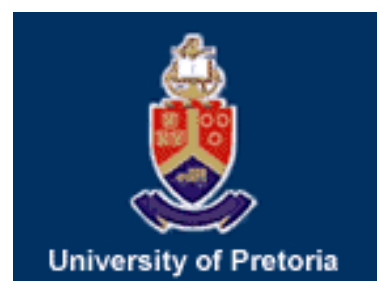

University of Pretoria

Department of Economics Working Paper Series

\title{
The Minimal Confidence Levels of Basel Capital Regulation
}

Alexander Zimper

University of Pretoria

Working Paper: 2013-05

January 2013

Department of Economics

University of Pretoria

0002, Pretoria

South Africa

Tel: +27124202413 


\title{
The minimal confidence levels of Basel capital regulation*
}

\author{
Alexander Zimper ${ }^{\dagger}$
}

January 24, 2013

\begin{abstract}
The Basel Committee on Banking Supervision sets the official confidence level at which a bank is supposed to absorb annual losses at $99.9 \%$. However, due to an inconsistency between the notion of expected losses in the Vasicek model, on the one hand, and the practice of Basel regulation, on the other hand, actual confidence levels are likely to be lower. This paper calculates the minimal confidence levels which correspond to a worst case scenario in which a Basel-regulated bank holds capital against unexpected losses only. I argue that the probability of a bank failure is significantly higher than the official $0.1 \%$ if, firstly, the bank holds risky loans and if, secondly, the bank was previously affected by substantial write-offs.

Keywords: Banking Regulation, Probability of Bank Failure, Definition of Expected Losses, Financial Stability

JEL Classification Numbers: G18, G32.
\end{abstract}

*I would like to thank Davy Corubolo and Guangling (Dave) Liu for helpful comments and suggestions. I am grateful to Alex Ludwig for helping me with the Matlab code.

${ }^{\dagger}$ Department of Economics, University of Pretoria, Private Bag X20, Hatfield 0028, South Africa. (O) 0027124203522 (F) 0027866912749. E-mail: alexander.zimper@up.ac.za 


\section{INTRODUCTION}

The Basel I accord required banks to hold capital such that the capital to risk-weighted asset ratio was not below $8 \%$. A theoretical drawback of this ad hoc approach to capital regulation was the seeming arbitrariness of the $8 \%$ ratio as well as of the prescribed risk-weights. The internal ratings based (=IRB) approach of the Basel II and III accord attempts to address this drawback by introducing the Value-at-Risk (=VaR) criterion as its theoretical foundation for capital regulation. Under the VaR criterion the regulator chooses a confidence level which supposedly stands for the bank's survival probability over the next year.

The Basel Committee on Banking Supervision (=BCBS) sets the confidence level at a remarkably high $99.9 \%$. In other words: If the default risk was independent accross banks, a Basel-regulated banking system would result (in average) in one annual bank failure per one thousand banks. Similarly, if a bank's default risk was independent across time, this bank would fail (in average) once per one thousand years. Consequently, if we are exclusively concerned with credit risk-thereby abstracting from any further operational and market risks-the Basel regulatory approach suggests that widespread bank failures will not be a problem in our lifetimes.

In the present paper I adopt the regulatory VaR approach of the BCBS. However, in contrast to the official line of argument by the BCBS, I demonstrate that the actual confidence level of a Basel-regulated bank might be much lower than the official 99.9\%. In particular, I argue that an inconsistency in the practice of Basel capital regulation gives rise to a worst case scenario in which a Basel-regulated bank only holds capital against unexpected but not against expected losses. In order to evaluate the actual confidence levels, I am going to calculate the probabilities of bank failures that correspond to this worst case scenario. Three main insights arise from my analysis:

1. The regulatory VaR approach only works if every single bank loan is fully covered against unexpected plus expected losses by the capital charge that correspond to the VaR at the specified confidence level.

2. Even if the Basel VaR approach is the correct model for a bank's VaR, the official 99.9\% confidence level of the Basel capital regulation might give us a false sense of security because the Basel regulatory capital only covers against unexpected but not against expected losses.

3. This false sense of security is especially severe for banks (i) which hold loans from risky obligors in their portfolio and (ii) which were previously affected by substantial impairments, resp. write-offs. 


\section{THE ISSUE UNDER CONSIDERATION}

This section provides a more technical introduction to the regulatory VaR approach. Let the continuous random variable $X^{B}$ denote the bank's annual percentage portfolio profit (expressed as decimals) so that $X=-1$ stands for the worst possible case according to which the bank will have lost $100 \%$ of its portfolio value after one year. ${ }^{1}$ Fix a confidence level $1-q$ and determine the $\operatorname{VaR}$ of $X^{B}$ at $q$ as the negative of the $q$-th quantile of $X^{B}$, i.e.,

$$
\operatorname{VaR}_{q}\left(X^{B}\right) \equiv-F^{-1}(q)
$$

with $F$ denoting the cumulative distribution function (=cdf) of $X$. If the bank holds the capital amount (1) as percentage of its portfolio value, it can absorb all annual losses up to the amount $-F^{-1}(q)$ so that the bank will survive with probability $1-q$ for another year. Suppose that the regulator possesses the correct model for (1). Then it remains for him to choose the bank's survival probability $1-q$ that is optimal from his perspective and to force the bank to hold (1) as percentage of its total exposure at default.

In order to come up with a parsimonious analytical expression for (1), the BCBS applies the Vasicek model. ${ }^{2,3}$ Consider the profit $X$ of a bucket portfolio, i.e., a portfolio that consists of a large number of loans to obligors such that (i) each obligor cannot repay the loan after one year with probability $\pi$ (default) whereby (ii) each loan's percentage loss-given-default is identically given as (expressed as decimals) $L G D$ and (iii) each loan's total exposure at default is identically given as $E A D$. Furthermore, suppose that the correlation coefficient between any two obligors' asset values is given as $\rho$. Under the assumptions of the Vasicek model, we then obtain the following analytical expression of (1) for the VaR of a bucket portfolio (see the subsequent section for a detailed discussion):

$$
\begin{aligned}
& \operatorname{VaR}_{q}(X) \\
= & \Phi\left(\frac{\Phi^{-1}(\pi(\text { default }))+\sqrt{\rho} \cdot \Phi^{-1}(1-q)}{\sqrt{1-\rho}}\right) \cdot L G D
\end{aligned}
$$

where $\Phi$ denotes the cdf of the standard normal distribution. The Vasicek-formula (2) is a special case of the single-factor models investigated in Schoenbucher ${ }^{4}$ and Gordy ${ }^{5}$ for which the portfolio invariance principle holds. According to this principle, an added or withdrawn capital-charge of (2) for any loan added or withdrawn will keep the overall bucket portfolio covered at an $1-q$ confidence level. As a consequence, the overall bucket portfolio will survive at the $1-q$ confidence level if every single loan within the bucket is charged at $\operatorname{VaR}_{q}(X)$ percent of its $E A D$.

Going beyond the Vasicek model, the Basel accord stipulates that the correlation coefficient in the Vasicek-formula (2) can be described as a function in the obligors' default probability such that $\rho$ is exponentially decreasing in $\pi$ (default) with values in 
the interval $(0.12,0.24)$ for loans to corporate and sovereign obligors and, since Basel III, in the interval $(0.15,0.3)$ for loans to financial obligors. The Basel accord also stipulates that either the overall bank portfolio is already given as some bucket portfolio or it consists of several bucket portfolios such that the VaRs of all $X$ at $q$ add up to the VaR of $X^{B}$ at $q$. That is, the Basel accord presumes that a capital charge of $V a R_{q}(X)$ for each bucket portfolio will add up to the capital $\operatorname{Va} R_{q}\left(X^{B}\right)$ necessary for covering the whole bank at an $1-q$ confidence level. Under the above (strong) assumptions, the Basel VaR approach comes thus up with a parsimonious analytical formula for the capital charge of any given bank loan's EAD that only depends on (i) the obligor's default probability and (ii) the obligor's loss-given-default.

In a final step, the BCBS sets the confidence level at 99.9\%. However, at this point some inconsistency between the Vasicek model and the practice of Basel capital regulation arises. Instead of requiring the capital charge $\operatorname{VaR}_{0.001}(X)$, which would cover for losses at the $99.9 \%$ confidence level, the Basel accord splits up $V_{a} R_{0.001}(X)$ into expected versus unexpected losses. On the one hand, the Basel accord "requires" regulatory capital, denoted $K^{\text {Basel }}$, to be held against unexpected losses only. However, on the other hand, the Basel accord "expects" banks to somehow hold capital against expected losses. In practice these expected losses are supposedly covered by write-downs and impairments for unhealthy loans. However, this practice is in contrast to the notion of expected losses in the Vasicek model which refers to the average losses of currently healthy loans that will occur in one year's time. Due to this inconsistency in the Basel capital regulation, the actual amount of capital held by a Basel-regulated bank can be expected to fall somewhere into the interval

$$
\left[K^{\text {Basel }}, \operatorname{VaR} R_{0.001}(X)\right]
$$

whereby

$$
K^{\text {Basel }}=\operatorname{VaR}_{0.001}(X)-\pi(\text { default }) \cdot L G D
$$

because the percentage of expected losses coincides under the Vasicek model with each obligor's (unconditional) probability of default times the loss-given default.

The interval of possible Basel capital levels (3) corresponds to the following interval of possible confidence levels

$$
\left[1-q^{*}, 0.999\right]
$$

such that the Basel-regulated bank absorbs losses at the minimal confidence level $1-q^{*}$ whenever it only holds capital $K^{\text {Basel }}$. Formally, the value of $q^{*}$ is pinned down by the equation

$$
\operatorname{VaR}_{q^{*}}(X)=K^{\text {Basel }} .
$$


As this paper's main contribution, I calculate the values of the minimal confidence levels $1-q^{*}$. In contrast to the maximal confidence level, which is fixed at 0.999 for all probabilities of default, the minimal confidence level $1-q^{*}$ is a strictly decreasing function in the obligor's default probability. Our numerical results show that the minimal confidence levels become significantly smaller than the $99.9 \%$ when the probability of an obligor's default increases. For example, whereas at 0.2 probability of default the minimal capital $K^{\text {Basel }}$ can still absorb losses at an $95.6 \%$ confidence level, it can only absorb losses at an $83.6 \%$ confidence level when the probability of default rises to 0.3 , and at an $54 \%$ confidence level when the probability of default rises to 0.4 .

\section{THE BASEL VaR APPROACH}

Throughout this paper I assume that the Basel approach towards the specification of the VaR of a bank portfolio (1) is indeed the correct one; or at least sufficiently close to reality. Nevertheless, the reader should be aware that the Basel VaR approach is based on the following (strong) assumptions: ${ }^{6}$

1. Whether a bank loan will be repaid after one year by any given obligor or not, is completely determined by the obligor's value process formally described as Geometric Brownian motion.

2. There exist bucket portfolios which contain a large number of (sufficiently finegrained) obligors whose value processes are equicorrelated so that there exists a single systemic risk-factor per bucket portfolio.

3. The correlation coefficients for the loans within any given bucket portfolio are correctly reflected by the Basel formula.

4. The loss-given-default of any obligor is the same for all values of the systemic factor.

5. Either a bank is already given as a single bucket portfolio or the absolute VaRs of the bank's bucket portfolios are supposed to be additive.

Because the correct understanding of the Basel VaR approach is central to this paper, the remainder of this Section sketches in some detail the reasoning behind this approach. For expositional convenience, I thereby restrict attention to the simple case of bucket portfolios which contain loans with identical $E A D$ and $L G D$. For a technically more general analysis of single-factor conditionally independent models, I would like to refer the reader to Schoenbucher ${ }^{4}$, Vasicek ${ }^{2,3}$, Gordy $^{5}$, and Thomas and Wang ${ }^{7}$. 


\section{The obligor's asset value process}

Suppose that the bank's assets are characterized as loans to obligors. Whether any given obligor pays back this loan in period $t$, depends on whether this obligor will have defaulted in $t$ or not. Such a default occurs if and only if the obligor's time $t$ absolute asset value falls below some threshold $K$. Following Vasicek, the Basel accord thereby assumes that an obligor' asset value process is given as geometric Brownian motion. More specifically, let us identify the value process of an obligor's asset as

$$
\begin{aligned}
d A(t) & =\alpha \cdot A(t) d t+\sigma \cdot A(t) d W(t) \\
A(0) & =a_{0}
\end{aligned}
$$

with $W$ denoting a Wiener process. By an application of Itô's formula - and according integration - it can easily be $\operatorname{shown}^{8}$ that the log value of the obligor's asset at period $t$ is given as

$$
\log A(t)=\ln a_{0}+\mu \cdot t+\sigma \cdot W(t)
$$

where

$$
\mu=\alpha-\frac{1}{2} \sigma^{2} .
$$

Furthermore, recall that a Wiener process satisfies

$$
\begin{aligned}
W(0) & =0 \\
E(W(t)-W(0)) & =0 \\
\operatorname{var}(W(t)-W(0)) & =t .
\end{aligned}
$$

Consequently, we can equivalently rewrite (9) as

$$
\log A(t)=\log a_{0}+\mu \cdot t+\sigma \cdot \sqrt{t} \cdot V(t)
$$

whereby

$$
V(t)=\frac{W(t)-E(W(t))}{\operatorname{var}(W(t))}
$$

has a standard normal distribution. To characterize the default probability of the obligor at time $t$ observe that

$$
\begin{aligned}
\pi(\text { default }) & =\pi(A(t)<K) \\
& =\pi(\log A(t)<\log K) \\
& =\pi(V(t)<k) \\
& =\Phi(k)
\end{aligned}
$$


such that

$$
k \equiv \frac{\log K-\log a_{0}-\mu \cdot t}{\sigma \cdot \sqrt{t}}
$$

where $\Phi$ denotes the cdf of the standard normal distribution.

It is important to observe that the above approach defines an obligor's default as an event that happens exactly at time $t$, i.e., when the asset value $A(t)$ is compared to the threshold $K$, and not at any time between 0 and $t$ as it is implicitly assumed by the practice of Basel capital regulation with respect to expected losses. In what follows, we simply write $V$ for the asset value $V(t)$ such that $t$ is given as one year which is the relevant time-span for the Basel regulation.

\section{The large Bucket portfolio}

Consider $n$ obligors whose asset value processes are described by (7). We collect the $n$ loans to these obligors within a bucket portfolio if the following assumptions are satisfied. First, there exists a common correlation coefficient $\rho$ between the log asset values of any two obligors $i$ and $j, i, j\{\in 1, \ldots, n\}$; that is, the obligors' asset values are equicorrelated. Second, all obligors are characterized by an identical $L G D$ and $E A D$. Whereas the equicorrelation assumption is crucial to the Vasicek model, the identical $L G D$ and $E A D$ assumption is merely for expositional convenience and can be easily generalized..$^{3,5}$

The jointly standard normal and equicorrelated asset-values can be decomposed for each obligor $i$ into

$$
V_{i}=\sqrt{\rho} \cdot Y+\sqrt{1-\rho} \cdot \varepsilon_{i}
$$

whereby $Y$ and $\varepsilon_{i}, i \in\{1, \ldots, n\}$, are independent and identically standard normal distributed. $Y$ is interpreted as the systemic factor common to all obligors in the bucket portfolio whereas $\varepsilon_{i}$ is a factor idiosyncratic to obligor $i$. Conditioning the event of default of obligor $i$ on the systemic factor $Y$, we obtain

$$
\begin{aligned}
\pi(\text { default } \mid Y=y) & =\pi\left(V_{i}<k \mid Y=y\right) \\
& =\pi\left(\varepsilon_{i}<\frac{k-\sqrt{\rho} \cdot y}{\sqrt{1-\rho}}\right) \\
& =\Phi\left(\frac{k-\sqrt{\rho} \cdot y}{\sqrt{1-\rho}}\right) .
\end{aligned}
$$

Substituting

$$
k=\Phi^{-1}(\pi(\text { default }))
$$

in (24) gives us the so-called Vasicek formula (cf. Equation (3) in Vasicek ${ }^{3}$ )

$$
\pi(\text { default } \mid Y=y)=\Phi\left(\frac{\Phi^{-1}(\pi(\text { default }))-\sqrt{\rho} \cdot y}{\sqrt{1-\rho}}\right) .
$$


Define the systemic loss $L_{Y}=-Y$ and equivalently rewrite (26) as follows

$$
\begin{aligned}
\pi\left(\text { default } \mid L_{Y}=l_{Y}\right) & =\pi\left(\text { default } \mid Y=-l_{Y}\right) \\
& =\Phi\left(\frac{\Phi^{-1}(\pi(\text { default }))+\sqrt{\rho} \cdot l_{Y}}{\sqrt{1-\rho}}\right)
\end{aligned}
$$

Conditional on the systemic loss $L_{Y}=l_{Y}$ the standardized log values $V_{i}$ of all assets $i \in\{1, \ldots, n\}$ in the bucket are i.i.d.. The law of large numbers therefore implies that $\pi$ (default $\mid L_{Y}=l_{Y}$ ) will coincide (almost surely) with the proportion of loans in a given bucket which default under $L_{Y}=l_{Y}$ if the number of obligors $n$ in the bucket

gets large. Let $X$ denote the percentage profit of the bucket portfolio after one year and observe that for large $n$ the loss of the bucket portfolio is thus given as the random variable

$$
\begin{aligned}
L_{X} & \equiv-X \\
& =\pi\left(\text { default } \mid L_{Y}\right) \cdot L G D
\end{aligned}
$$

such that $\pi$ (default $\left.\mid L_{Y}\right)$ is given by $(27)$.

\section{Confidence levels for systemic losses versus portfolio losses}

Fix a confidence level $1-q$ for the systemic factor and observe that we have for the Vasicek model

$$
\operatorname{VaR}_{q}(Y)=-\Phi^{-1}(q)
$$

The following proposition establishes that covering the bucket portfolio against systemic losses at an $1-q$ confidence level is equivalent to covering the bucket portfolio against portfolio losses at an $1-q$ confidence level.

Proposition. Consider a large bucket portfolio with random percentage profit $X$. For the Vasicek model it holds that

$$
\operatorname{VaR}_{q}(X)=\pi\left(\text { default } \mid L_{Y}=\operatorname{VaR}_{q}(Y)\right) \cdot L G D
$$

such that

$$
\begin{aligned}
& \pi\left(\text { default } \mid L_{Y}=\operatorname{VaR}_{q}(Y)\right) \\
= & \Phi\left(\frac{\Phi^{-1}(\pi(\text { default }))+\sqrt{\rho} \cdot \Phi^{-1}(1-q)}{\sqrt{1-\rho}}\right) .
\end{aligned}
$$


Proof: Rewrite the portfolio losses as a function of systemic losses

$$
\begin{aligned}
l_{X} & =\Phi\left(\frac{\Phi^{-1}(\pi(\text { default }))+\sqrt{\rho} \cdot l_{Y}}{\sqrt{1-\rho}}\right) \cdot L G D \\
& \equiv g\left(l_{Y}\right)
\end{aligned}
$$

and observe that $g(\cdot)$ is strictly increasing in $l_{Y}$, i.e.,

$$
l_{Y}>l_{Y}^{\prime} \Leftrightarrow g\left(l_{Y}\right)>g\left(l_{Y}^{\prime}\right) .
$$

Consequently,

$$
\begin{aligned}
\operatorname{pr}\left(L_{X} \geq l_{X}\right) & =\operatorname{pr}\left(g\left(L_{X}\right) \geq g\left(l_{X}\right)\right) \\
& =\operatorname{pr}\left(L_{Y} \geq l_{Y}\right) .
\end{aligned}
$$

Let

$$
\begin{aligned}
\operatorname{pr}\left(L_{Y} \geq l_{Y}\right) & =q \\
& \Leftrightarrow \\
l_{Y} & =\operatorname{VaR}_{q}(Y)
\end{aligned}
$$

and observe that

$$
\begin{aligned}
\operatorname{pr}\left(L_{Y} \geq l_{Y}\right) & =\operatorname{pr}\left(g\left(L_{X}\right) \geq g\left(\operatorname{VaR}_{q}(Y)\right)\right) \\
& =\operatorname{pr}\left(L_{X} \geq l_{X}\right)
\end{aligned}
$$

such that

$$
\begin{aligned}
\operatorname{pr}\left(L_{X} \geq l_{X}\right) & =q \\
& \Leftrightarrow \\
l_{X} & =\operatorname{VaR}_{q}(X) .
\end{aligned}
$$

This proves

$$
\begin{aligned}
\operatorname{VaR}_{q}(X) & =g\left(\operatorname{VaR}_{q}(Y)\right) \\
& =\Phi\left(\frac{\Phi^{-1}(\pi(\text { default }))+\sqrt{\rho} \cdot \operatorname{VaR}(Y)}{\sqrt{1-\rho}}\right) \cdot L G D .
\end{aligned}
$$

Finally, observe that we have for the standard normally distributed systemic factor

$$
\begin{aligned}
\operatorname{VaR}_{q}(Y) & =-\Phi^{-1}(q) \\
& =\Phi^{-1}(1-q)
\end{aligned}
$$




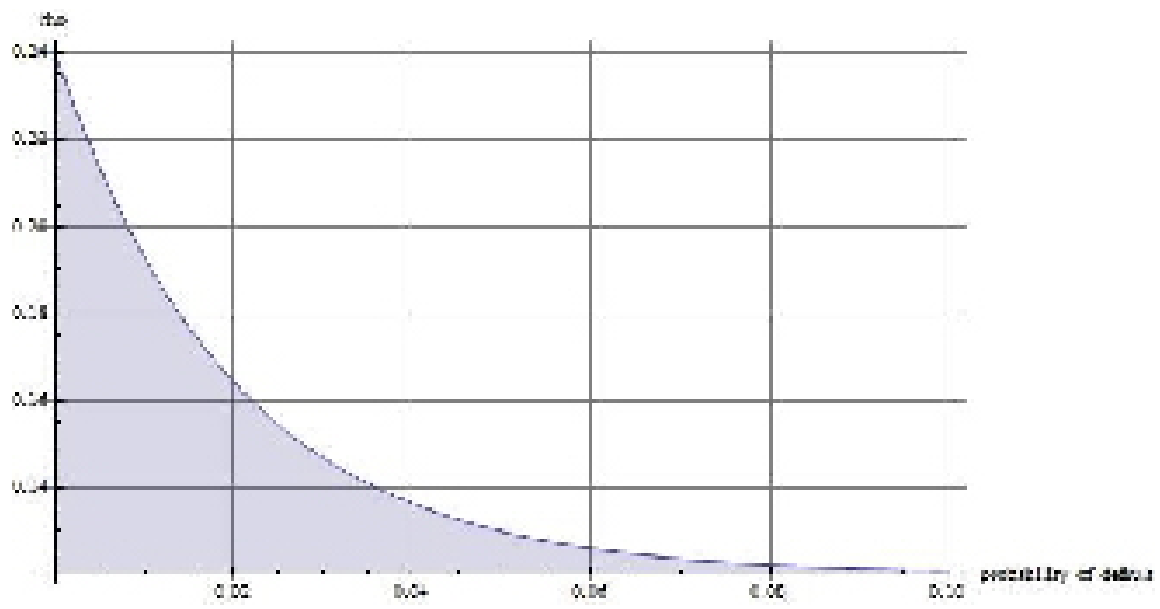

Figure 1: The Basel correlation coefficient for loans to corporate and sovereign obligors

which proves the proposition.

The above proposition for the Vasicek model can be regarded as a special case of Gordy's Proposition 4 which considers a more general notion of bucket portfolios than we do. ${ }^{5}$

\section{Obligor correlation}

The VaR of the bucket portfolio, given by (31), has been exclusively derived by an application of the Vasicek model for which the correlation coefficient $\rho$ is an exogenous parameter. To come up with a parsimonious formula for regulatory capital charges, the Basel VaR approach endogenizes $\rho$ by describing it as an exponential function in the probability of default $\pi$ (default). More specifically, the Basel II accord defines ${ }^{9}$

$$
\begin{aligned}
\rho & \equiv \rho(\pi(\text { default })) \\
& =0.12 \cdot(1-\exp (-50 \cdot \pi(\text { default })))+0.24 \cdot \exp (-50 \cdot \pi(\text { default })) .
\end{aligned}
$$

Figure 1 shows that (49) quickly decreases from its least upper bound at 0.24 to its greatest lower bound at 0.12 .

The realistic appeal of the one-size-fits-it all formula (49) is questionable. For example, in the aftermath of the financial crisis the BCBS already observes:

"Large financial institutions were more interconnected than currently reflected in the capital framework [i.e., Basel II, the author]. As a result, when markets entered the downturn, banks' counterparty exposure to other 
financial firms also increased. The evidence suggests that the asset values of financial firms are, on a relative basis, more correlated than those of nonfinancial firms." (BCBS 2009, p. 28f $)^{10}$

As a consequence, Basel III has revised (49) for loans to financial obligors as follows

$$
\begin{aligned}
& \rho(\pi(\text { default })) \\
= & 0.15 \cdot(1-\exp (-50 \cdot \pi(\text { default })))+0.3 \cdot \exp (-50 \cdot \pi(\text { defaul }))
\end{aligned}
$$

so that (50) takes on values between 0.15 and 0.3 .

\section{Additivity of bucket VaRs}

Finally, the Basel accord stipulates that the absolute VaR of the bank portfolio, which aggregates over all bucket portfolios within the bank, is additive in the absolute VaRs of the bank's bucket portfolios. More precisely, suppose that there are $k=1, \ldots, m$ different large bucket portfolios within a bank with corresponding percentage $\operatorname{VaR}_{q}\left(X_{k}\right)$ and absolute portfolio values $E A D_{k}$. The bank's percentage portfolio profit is then defined as

$$
X^{B} \equiv \frac{\sum_{k=1}^{m} X_{k} \cdot E A D_{k}}{\sum_{k=1}^{m} E A D_{k}} .
$$

The Basel accord, implicitly, assumes that

$$
\begin{aligned}
& \operatorname{VaR}_{q}\left(X^{B} \cdot \sum_{k=1}^{m} E A D_{k}\right)=\sum_{k=1}^{m} \operatorname{VaR}_{q}\left(X_{k} \cdot E A D_{k}\right) \\
& \operatorname{VaR}_{q}\left(X^{B}\right) \cdot \sum_{k=1}^{m} E A D_{k}=\sum_{k=1}^{m} \operatorname{VaR}\left(X_{k}\right) \cdot E A D_{k}
\end{aligned}
$$

whereby the second line follows from the positive homogeneity of the VaR criterion. If and only if additivity (52) holds, then the percentage capital charge $\operatorname{VaR}_{q}\left(X_{k}\right)$ at confidence level $1-q$ for every bucket portfolio $k$ ensures that the aggregate capital $\sum_{k=1}^{m} \operatorname{VaR}_{q}\left(X_{k}^{B}\right) \cdot E A D_{k}$ covers the aggregate bank portfolio $\sum_{k=1}^{m} E A D_{k}$ at exactly the $1-q$ confidence level.

It is well known in the literature that the VaR criterion is, in general, not additive. ${ }^{11}$ Even worse from a regulatory perspective, the VaR criterion is not subadditive in the sense that we always have

$$
\operatorname{VaR}_{q}\left(X^{B}\right) \cdot \sum_{k=1}^{m} E A D_{k} \leq \sum_{k=1}^{m} \operatorname{VaR}\left(X_{k}\right) \cdot E A D_{k} .
$$


Consequently, there exist perceivable bucket portfolio profit distributions such that (54) is violated to the effect that the percentage capital charges $\operatorname{Va} R_{q}\left(X_{k}\right)$, which cover every bucket portfolio at a confidence level $1-q$, are not sufficient to cover the bank's overall portfolio at the $1-q$ confidence level.

\section{MINIMAL CONFIDENCE LEVELS OF BASEL REG- ULATION}

Regardless of the strong assumptions underlying the Basel VaR approach, let us suppose that it is sufficiently close to the true VaR of a bank portfolio (1). Let us also assume that the bank's internal rating truthfully comes up with good estimates for $\pi$ (default) and $L G D$ for each bucket portfolio. Then the regulator is in the convenient position to enforce any desired confidence level $1-q$ on the bank by requiring the capital charge (2) for every individual bank loan. This section critically investigates the actual Basel approach towards regulatory capital.

\section{Regulatory capital}

The BCBS states:

"The confidence level is fixed at $99.9 \%$, i.e. an institution is expected to suffer losses that exceed its level of tier 1 and tier 2 capital on average once in a thousand years." (BCBS 2005, p.11) ${ }^{12}$

To cover for losses at the $99.9 \%$ confidence level under the Basel VaR approach, the bank would have to cover every single loan by the following capital charge in percent of the loan's $E A D$

$$
\begin{aligned}
& \operatorname{VaR}_{0.001}(X) \\
= & \Phi\left(\frac{\Phi^{-1}(\pi(\text { default }))+\sqrt{\rho(\pi(\text { default }))} \cdot \Phi^{-1}(0.999)}{\sqrt{1-\rho(\pi(\text { default }))}}\right) \cdot L G D
\end{aligned}
$$

with $\rho(\pi$ (default)) given by (49) (or by (50) for loans to financial obligors). Figure 2 shows the required capital charge as a function of the obligors' probability of default for $L G D=1$ (for $L G D=x$ just multiply the capital charges by $x$ ).

Not surprisingly, the high confidence level of $99.9 \%$ corresponds to high capital charges. This might be one of the reasons that the actual Basel capital requirement 


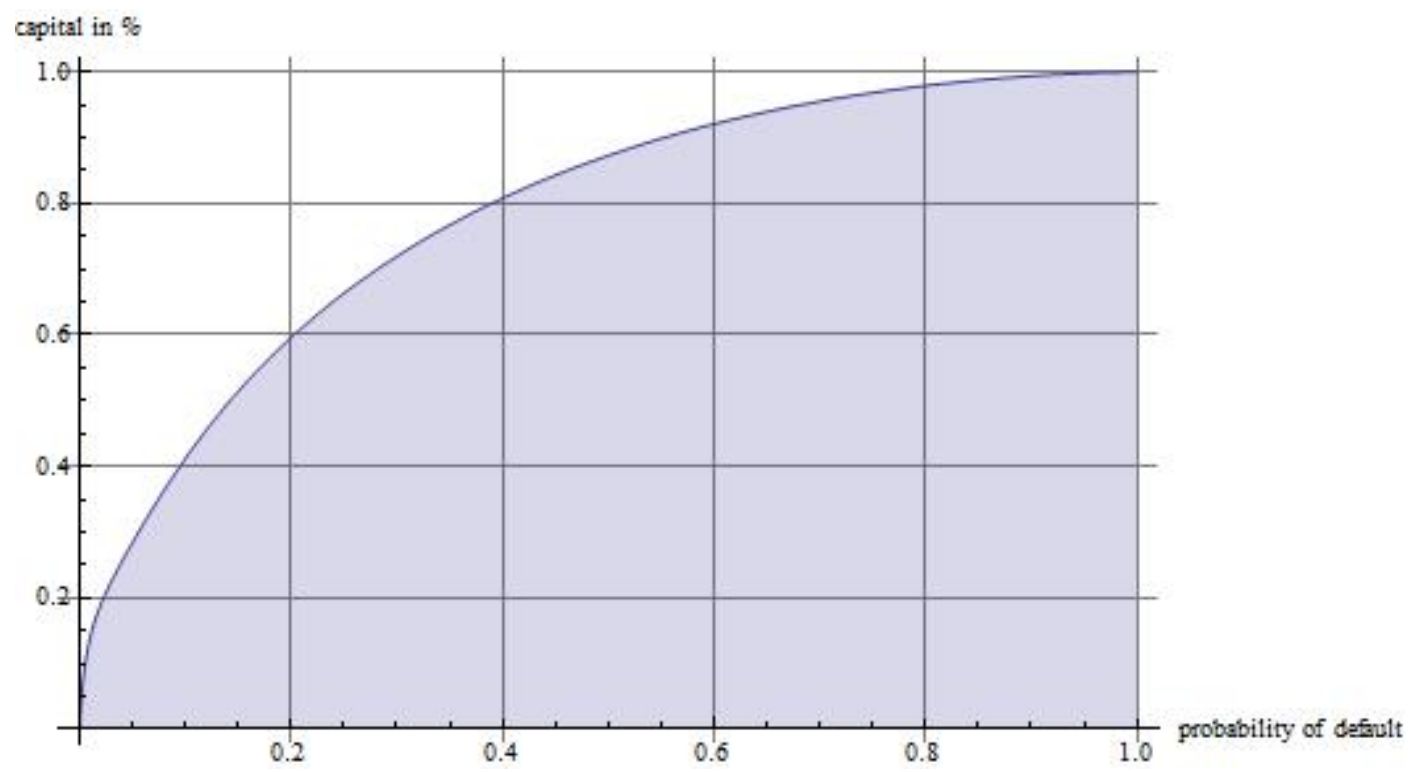

Figure 2: The capital charge at an $99.9 \%$ confidence level for $L G D=1$

had not been defined as $V a R_{0.001}(X)$ but rather as

$$
=\Phi\left(\frac{\Phi^{\text {Basel }}(\pi(\text { default }))+\sqrt{\rho(\pi(\text { default }))} \cdot \Phi^{-1}(0.999)}{\sqrt{1-\rho(\pi(\text { default }))}}-\pi(\text { default })\right) \cdot L G D .
$$

Figure 3 shows that the Basel regulatory capital $K^{\text {Basel }}$ strictly increases in the probability of default until it reaches a maximum at $\pi($ default $) \simeq 0.30976$. For higher default probabilities the required capital charge strictly decreases to zero.

\section{Expected versus unexpected losses}

Observe that we can equivalently write (56) as

$$
\begin{aligned}
K^{\text {Basel }} & =\operatorname{VaR}_{0.001}(X)-\pi(\text { default }) \cdot L G D \\
& =\operatorname{VaR}_{0.001}(X)-E L
\end{aligned}
$$

where the expected loss (=EL) of the Vasicek model is given as $\pi$ (de fault) $L G D$ because of

$$
\pi(\text { default }) \cdot L G D=\int_{Y}[\pi(\text { default } \mid y) \cdot L G D] d \pi(y) .
$$

That is, $\pi$ (default) $\cdot L G D$ is the average loss with respect to all possible realizations of the systemic factor $Y$. According to the Basel accord, the unexpected losses (=UL) are defined as the difference between $\operatorname{VaR}_{0.001}(X)$ and the expected losses so that the 


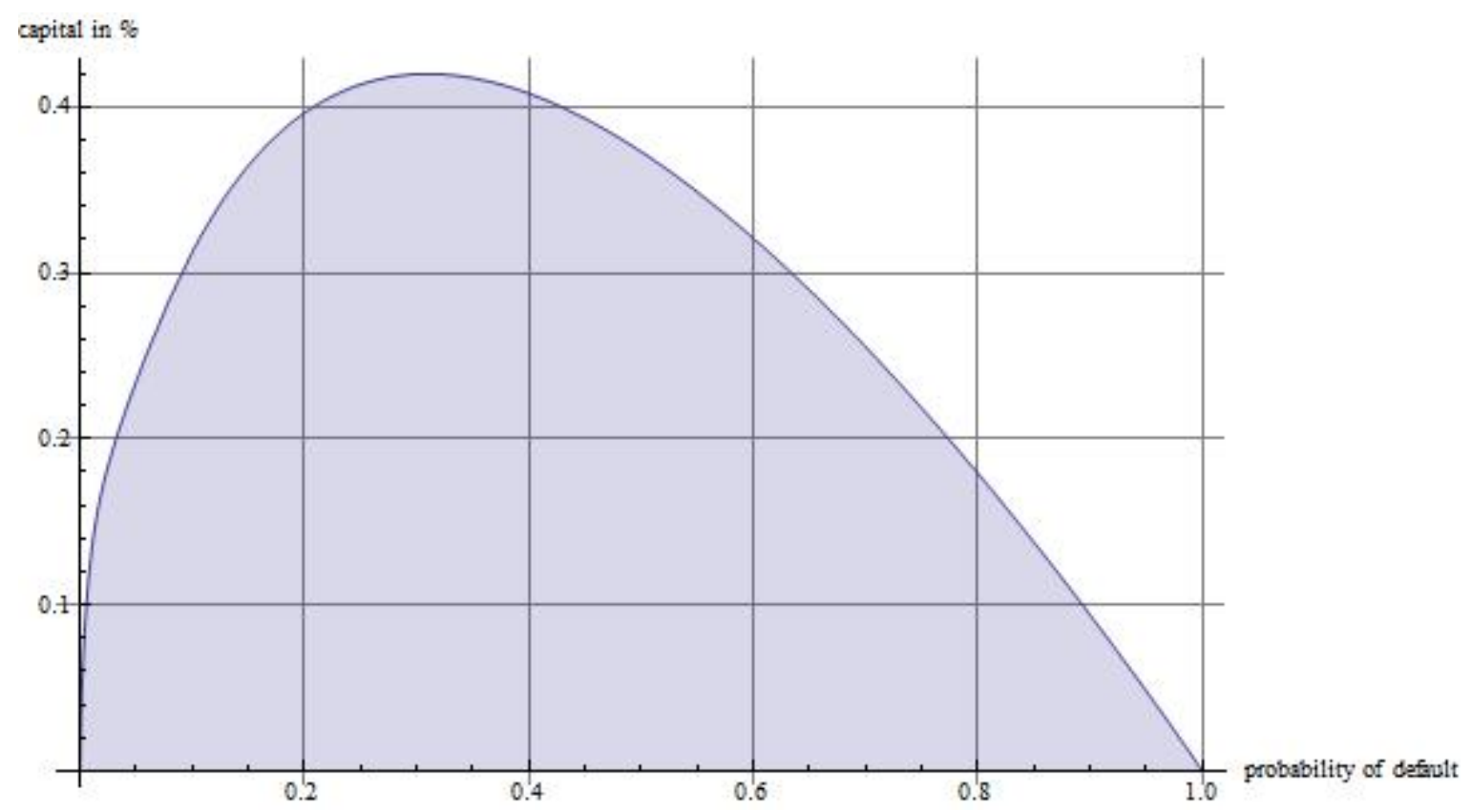

Figure 3: The required Basel capital charge for $L G D=1$

Basel regulatory capital (56) covers for the unexpected losses only. The BCBS offers the following explanation for this deviation from their VaR approach:

"[...] banks are expected in general to cover their Expected Losses on an ongoing basis, e.g. by provisions and write-offs, because it represents another cost component of the lending business. The Unexpected Loss, on the contrary, relates to potentially large losses that occur rather seldomly. According to this concept, capital would only be needed for absorbing Unexpected Losses. Nevertheless, it has to be made sure that banks do indeed build enough provisions against EL. Up to the Third Consultative Paper of the Basel Committee, banks had thus been required to include EL in the risk weighted assets as well. Provisions set aside for credit losses could be counted against the EL portion of the risk weighted assets - as such only reducing the risk weighted assets by the amount of provisions actually built. [...] In the end, it was decided to follow the UL concept and to require banks to hold capital against UL only. However, in order to preserve a prudent level of overall funds, banks have to demonstrate that they build adequate provisions against EL." (BCBS 2005, p. 7) ${ }^{12}$

Whereas the BCBS is clear about the regulatory capital requirement against unexpected losses, its dealing with expected losses is rather vague. To see how banks actually "demonstrate that they build adequate provisions against EL" consider, for instance, the 
following statement from the 2011 Risk and capital management report of the Standard Bank Group:

"Banks compare the IRB measurement of expected losses with the total amount of impairments that they have recognised in terms of IFRS [=International Financial Reporting Standards, the author], including both portfolio and specific impairments. For any individual bank, this comparison produces a shortfall if the expected loss amount exceeds total impairments, or an excess if total impairments exceed the expected loss amount.

Shortfall amounts, if any, are deducted from capital in the ratio of $50 \%$ from tier I capital and 50\% from tier II capital." (p. 11) ${ }^{13}$

Under the assumptions of the Basel VaR approach, it is imperative that every single loan is covered by a capital charge that takes future expected plus unexpected losses of this specific loan into account. However, IFRS impairments are triggered by some credit event, i.e., when a loan turns unhealthy. The practice of the Standard Bank Group to offset IFRS impairments against expected losses of the Vasicek model therefore amounts to offsetting realized losses of previous loans against future average losses of current loans. As a consequence, these currently healthy loans will not be fully covered against their expected losses whenever impairments reflecting losses on previous loans are deduced from the capital charge for these current loans. The Standard Bank Group would thus hold the maximal capital amount $\operatorname{Va} R_{0.001}(X)$ only if there were no previous impairments whereas it would only hold the minimal capital amount $K^{\text {Basel }}$ if these impairments exceeded the expected losses.

Conceptually an inconsistency has crept into the practice of the Basel regulation because the deduction of IFRS impairments from the capital base is altogether different from making provisions against expected losses in one year's time as required by the Vasicek model. This inconsistency between the Vasicek model and the actual Basel regulation points to a dangerous dynamic: If a Basel-regulated bank had suffered through a bad year resulting in substantial impairments, then its capital coverage for next year losses will be closer to $K^{\text {Basel }}$ than to $V a R_{0.001}(X)$. That is, banks that were previously affected by substantial write-offs of unhealthy loans will-in perfect accordance with the practice of Basel regulation-only hold capital against unexpected but not against expected losses.

\section{Minimal confidence levels}

Because of the inconsistency in the Basel regulation's dealing with expected losses, the capital of a Basel-regulated bank will be somewhere in the interval (3). As our main 
contribution we calculate the confidence levels at which a Basel-regulated bank absorbs losses when it only holds the minimal capital (56).

Formally, the minimal confidence level, denoted $1-q^{*}$, is determined by the equation

$$
\operatorname{VaR} R_{q^{*}}(X)=K^{\text {Basel }}
$$

which is, under the Basel VaR approach, equivalent to

$$
\begin{aligned}
& \Phi\left(\frac{\Phi^{-1}(\pi(\text { default }))+\sqrt{\rho(\pi(\text { default }))} \cdot \Phi^{-1}\left(1-q^{*}\right)}{\sqrt{1-\rho(\pi(\text { default }))}}\right) \\
= & \Phi\left(\frac{\Phi^{-1}(\pi(\text { default }))+\sqrt{\rho(\pi(\text { default }))} \cdot \Phi^{-1}(0.999)}{\sqrt{1-\rho(\pi(\text { default }))}}\right)-\pi(\text { default }) .
\end{aligned}
$$

I present numerical values for $q^{*}$ in the Appendix for default probabilities between 0.01 and $0.5 .^{14}$

Recall that $q^{*}$ stands for the probability that the bank will have failed after one year because more obligors default than it was covered for by the regulatory capital $K^{\text {Basel }}$. Observe that $q^{*}$ is a function in $\pi$ (default) but not in $L G D$. Not surprisingly, $q^{*}$ turns out to be a strictly increasing function in the obligor's default probability. In other words: The minimal confidence level $1-q^{*}$ is a strictly decreasing function in the obligor's default probability. Figure 4 shows the values of $q^{*}$ for $\pi$ (de fault) $\in[0.01,0.5]$ whereas Figure 5 zooms in on $\pi$ (default) $\in[0.01,0.1]$.

In contrast to the official 99.9\% confidence level of Basel regulation, which is fixed for all probabilities of obligors' default, the minimal confidence levels which result when a bank only holds $K^{\text {Basel }}$ as capital are highly sensible to the obligors' probability of default. For moderate values of $\pi$ (default), $q^{*}$ is strictly convex; that is, the gap between $q^{*}$ and the official Basel value of $q=0.001$ increases in an accelerated way on the interval $[0.01,0.3]$. For very small values of $\pi$ (default) the minimal confidence level $1-q^{*}$ stays close to the official confidence level $1-q=0.999$. However, at $\pi$ (default) $=0.1$ the

probability $q^{*}$ of a bank failure after one year is already about nine times higher than the 0.001 probability stipulated by the Basel regulation. At $\pi$ (default) $=0.26$ the probability of a bank failure is at 0.1 and at $\pi$ (default $)=0.315$ it is already at 0.2 . Finally, at the high default probability $\pi($ default $)=0.5$ the probability of a bank failure is at 0.81 !

\section{CONCLUDING REMARKS}

A full-blown economic model of optimal banking regulation would have to model some trade-off between the perceived economic costs of a bank failure, on the one hand, and 


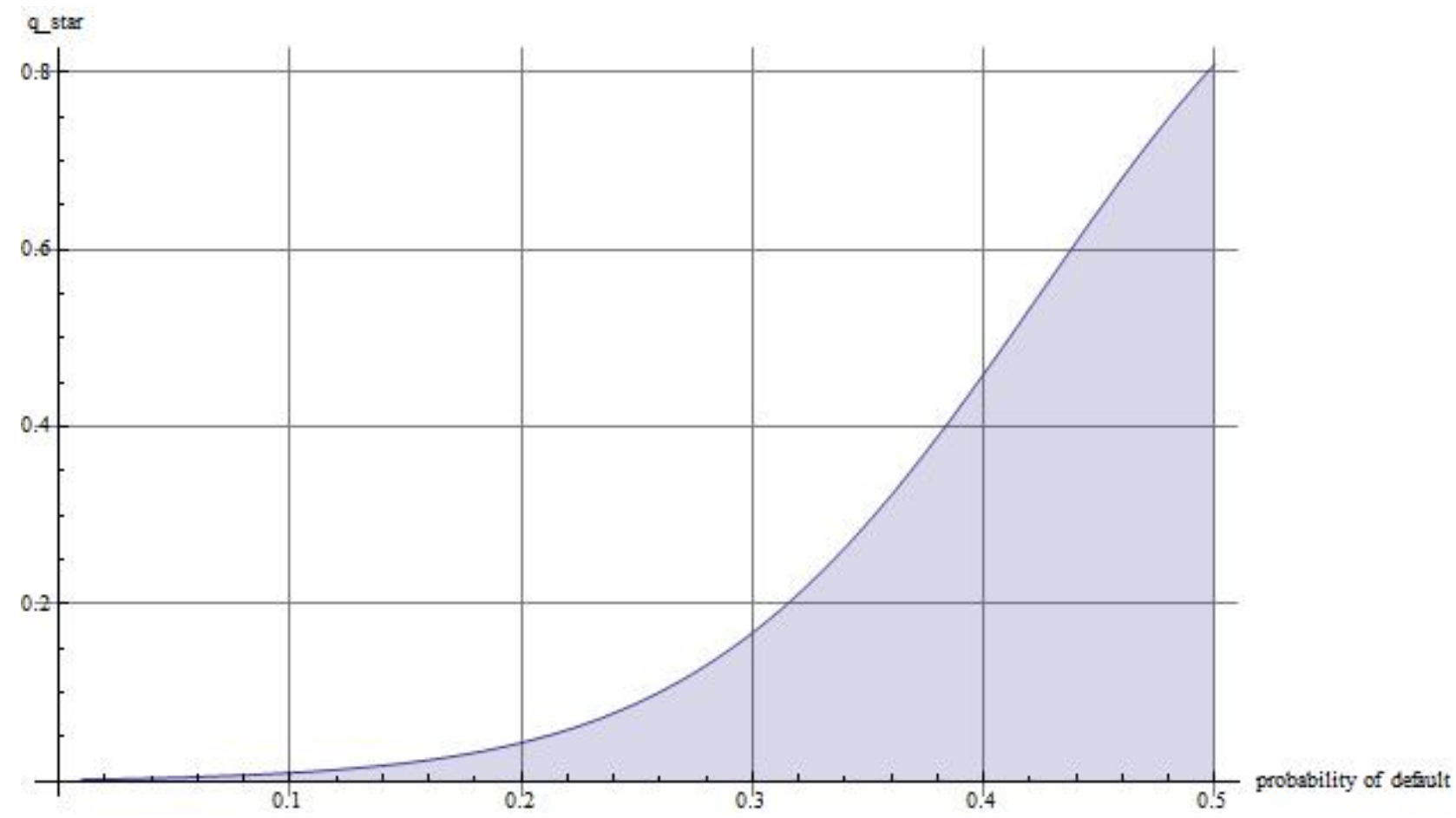

Figure 4: The annual bank failure probability $q^{*}$ at $K^{\text {Basel }}$

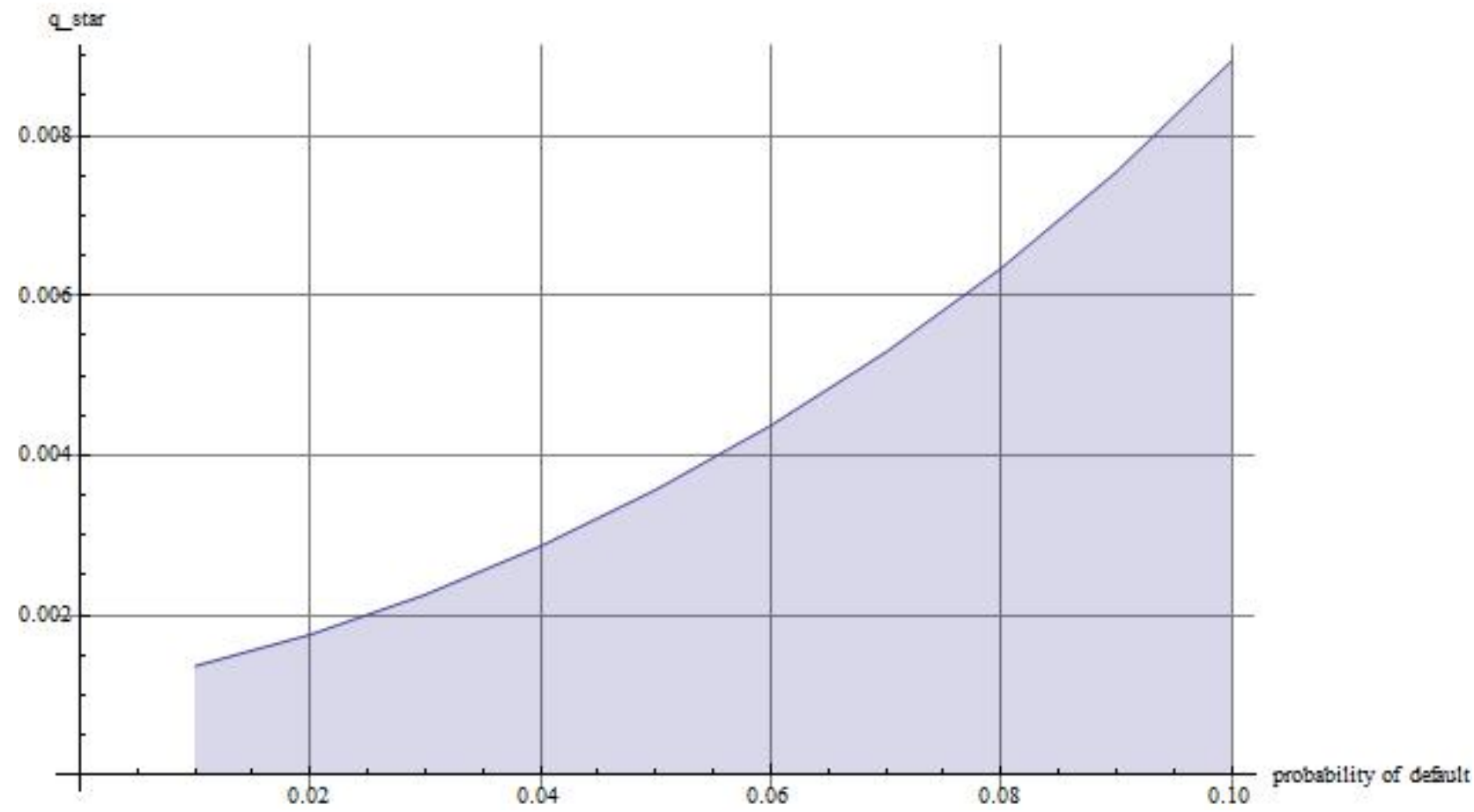

Figure 5: The annual bank failure probability $q^{*}$ zoomed in on $[0.01,0.1]$ 
the benefits of a bank's lending to risky obligors, on the other hand. ${ }^{15-18}$ The scope of the present paper has been considerably narrower. First, I exclusively describe the risk of a bank's failure in terms of credit risk whereby I neglect any further aspects of operational and market risks. Second, I have accepted the official confidence level of $99.9 \%$ as the regulator's solution to the optimal trade-off between bank failure and lending activity. In a next step, I have asked whether the Basel accord actually covers a bank at this $99.9 \%$ confidence level under the assumption that the Basel VaR formula is a correct description of the bank's true VaR. At this point, I have identified an inconsistency between the Basel VaR approach and the practice of Basel regulation concerning the capital coverage of expected losses. More specifically, I argue that the practice of treating impairments for unhealthy loans as provisions for future expected losses may result in a worst case scenario in which the bank's capital only covers against unexpected losses.

In order to evaluate this worst case scenario of the financial stability of a Baselregulated banking system, I have calculated the minimal confidence levels that correspond to the minimal regulatory capital required by the Basel accord. These minimal confidence levels are strictly decreasing in the obligors' default probability so that the financial stability of a Basel-regulated banking system is likely to be more prone to bank failures than suggested by the official confidence level of $99.9 \%$. This would be especially true for banks that hold rather risky loans in their portfolio and that were previously affected by substantial write-offs of unhealthy loans. For these banks the probability of surviving for another year will be significantly lower than $99.9 \%$ despite the fact that they hold capital in accordance with the practice of Basel regulation. Note that this paper's analysis therefore offers a (partial) explanation for the empirical findings by Demirgüc-Kunt and Detragiache ${ }^{19}$ who argue that a bank's compliance with Basel regulation is not robustly associated with this bank's probability of survival. 


\section{APPENDIX: NUMERICAL VALUES FOR $q^{*}$}

The following table lists minimal confidence level values for selected default probabilities.

\begin{tabular}{|c|c|c|c|c|c|}
\hline \multicolumn{2}{|c|}{$\pi($ default $)$} & \multicolumn{2}{|c|}{$\pi($ default $) \quad q^{*}$} & \multicolumn{2}{|c|}{$\pi($ default $)$} \\
\hline 0.0100000 & 0.00136734 & 0.1485860 & 0.0195523 & 0.2822220 & 0.134086 \\
\hline 0.0149495 & 0.00154807 & 0.1535350 & 0.0211264 & 0.2871720 & 0.142729 \\
\hline 0.0198990 & 0.00175532 & 0.1584850 & 0.022819 & 0.2921210 & 0.151804 \\
\hline 0.0248485 & 0.00198953 & 0.1634340 & 0.0246381 & 0.2970710 & 0.161322 \\
\hline 0.0297980 & 0.00225015 & 0.1683840 & 0.0265924 & 0.3020200 & 0.171288 \\
\hline 0.0347475 & 0.00253632 & 0.1733330 & 0.0286907 & 0.3069700 & 0.181712 \\
\hline 0.0396970 & 0.00284721 & 0.1782830 & 0.0309425 & 0.3119190 & 0.192597 \\
\hline 0.0446465 & 0.0031823 & 0.1832320 & 0.0333575 & 0.3168690 & 0.203949 \\
\hline 0.0495960 & 0.00354154 & 0.1881820 & 0.0359459 & 0.3218180 & 0.215769 \\
\hline 0.0545455 & 0.00392542 & 0.1931310 & 0.0387184 & 0.3267680 & 0.228059 \\
\hline 0.0594949 & 0.00433495 & 0.1980810 & 0.041686 & 0.3317170 & 0.240817 \\
\hline 0.0644444 & 0.00477169 & 0.2030300 & 0.0448601 & 0.3366670 & 0.254041 \\
\hline 0.0693939 & 0.00523762 & 0.2079800 & 0.0482525 & 0.3416160 & 0.267725 \\
\hline 0.0743434 & 0.00573516 & 0.2129290 & 0.0518753 & 0.3465660 & 0.281864 \\
\hline 0.0743434 & 0.00573516 & 0.2178790 & 0.0557409 & 0.3515150 & 0.296446 \\
\hline 0.0792929 & 0.00626707 & 0.2228280 & 0.0598622 & 0.3564650 & 0.311461 \\
\hline 0.0842424 & 0.00683642 & 0.2277780 & 0.0642521 & 0.3614140 & 0.326895 \\
\hline 0.0891919 & 0.0074466 & 0.2327270 & 0.0689239 & 0.3663640 & 0.342732 \\
\hline 0.0941414 & 0.00810125 & 0.2376770 & 0.0738909 & 0.3713130 & 0.358952 \\
\hline 0.0990909 & 0.00880427 & 0.2426260 & 0.0791666 & 0.3762630 & 0.375535 \\
\hline 0.1040400 & 0.00955985 & 0.2475760 & 0.0847647 & 0.3812120 & 0.392456 \\
\hline 0.1089900 & 0.0103724 & 0.2525250 & 0.0906985 & 0.3960610 & 0.444986 \\
\hline 0.1139390 & 0.0112467 & 0.2574750 & 0.0969815 & 0.4109090 & 0.499502 \\
\hline 0.1188890 & 0.0121876 & 0.2624240 & 0.103627 & 0.4257580 & 0.555034 \\
\hline 0.1238380 & 0.0132005 & 0.2673740 & 0.110648 & 0.4406060 & 0.610496 \\
\hline 0.1287880 & 0.014291 & 0.2723230 & 0.118057 & 0.4554550 & 0.664753 \\
\hline 0.1337370 & 0.015465 & 0.2772730 & 0.125865 & 0.4703030 & 0.716684 \\
\hline 0.1386870 & 0.0167287 & 0.2822220 & 0.134086 & 0.4851520 & 0.765263 \\
\hline 0.1436360 & 0.0180888 & 0.2822220 & 0.134086 & 0.5000000 & 0.80962 \\
\hline
\end{tabular}




\section{REFERENCES AND NOTES}

1. I equivalently refer to a bank's portfolio value as the bank's total exposure at default.

2. Vasicek, O. (1991) Limiting loan loss probability distribution. KMV Corporation. http://www.moodysanalytics.com/ /media/Insight/Quantitative-Research/PortfolioModeling/91-08-09-Limiting-Loan-Loss-Probability-Distribution.ashx

3. Vasicek, O. (2002) Loan portfolio value. Risk 15: 160-162.

4. Schoenbucher, P. J. (2001) Factor models for portfolio credit risk. Journal of Risk Finance 3: 45-56.

5. Gordy, M. B. (2003) A risk-factor model foundation for ratings-based bank capital rules. Journal of Financial Intermediation 12: 199 - 232.

6. Note that this list of implicit or explicit assumptions of the Basel VaR approach might not be complete. For example, in Da-Rocha Lopes, S. and Nunes, T. (2010) A simulation study on the impact of correlation between LGD and EAD on loss calculation when different LGD definitions are considered. Journal of Banking Regulation 11: 156-167. it is pointed out that the implicit Basel VaR assumption, according to which $L G D$ and $E A D$ are uncorrelated, might be violated in practice.

7. Thomas, H. and Wang, Z. (2005) Interpreting the internal ratings-based capital requirements in Basel II. Journal of Banking Regulation 6: 274-289.

8. Björk, T. (2009) Arbitrage Theory in Continuous Time. Oxford: Oxford University Press.

9. Throughout the paper I neglect the Basel firm size adjustment according to which the correlation between small firms is (slightly) lower than the correlation between large firms. I also simplify the original Basel definition

$$
\begin{aligned}
\rho(\pi(\text { default }))= & 0.12 \cdot \frac{(1-\exp (-50 \cdot \pi(\text { default })))}{1-\exp (-50)} \\
& +0.24 \cdot \frac{\exp (-50 \cdot \pi(\text { default }))}{1-\exp (-50)}
\end{aligned}
$$

because, for all practical purposes, $\exp (-50) \simeq 0$. 
10. BCBS (2009) Strengthening the Resilience of the Banking Sector: Consultative Document issued for comment by 16 April 2010. Bank for International Settlements. Basel.

11. Acerbi, C. and Tasche, D. (2002) On the coherence of expected shortfall. Journal of Banking \& Finance 26(7): 1487-1503.

12. BCBS (2005) An Explanatory Note on the Basel II IRB Risk Weight Functions. Bank for International Settlements. Basel.

13. Standard Bank Group (2011) Annual Integrated Report. Book II: Risk and Capital Management Report and Annual Financial Statements.

14. Fix $\pi$ (default) and observe that

$$
\Phi\left(\frac{\Phi^{-1}(\pi(\text { default }))+\sqrt{\rho(\pi(\text { default }))} \cdot \Phi^{-1}(1-q)}{\sqrt{1-\rho(\pi(\text { default }))}}\right)
$$

is strictly decreasing in $q$. To determine $q^{*}$ in (61) it is therefore sufficient to find the root $q^{*}$ of the univariate non-linear equation

$$
\begin{aligned}
& \Phi\left(\frac{\Phi^{-1}(\pi(\text { default }))+\sqrt{\rho(\pi(\text { default }))} \cdot \Phi^{-1}(1-q)}{\sqrt{1-\rho(\pi(\text { default }))}}\right) \\
& -\Phi\left(\frac{\Phi^{-1}(\pi(\text { default }))+\sqrt{\rho(\pi(\text { default }))} \cdot \Phi^{-1}(0.999)}{\sqrt{1-\rho(\pi(\text { default }))}}\right)-\pi(\text { default })=0
\end{aligned}
$$

I solve this using Brent's method (cf., e.g., Judd, K. (1999) Numerical Methods in Economics. MIT Press). The matlab code is provided at http://www.sfb504.unimannheim.de/ ${ }^{\text {zimper/solveq.m }}$

15. Kashyap, A. K. and Stein, J. C. (2004) Cyclical implications of the Basel II capital standard. Economic Perspectives. Federal Reserve Bank of Chicago.

16. Van den Heuvel, S. (2008) The welfare cost of bank capital requirements. Journal of Monetary Economics 55(2): 298-320.

17. Acharya, S. (2009) A theory of systemic risk and design of prudential bank regulation. Journal of Financial Stability 5: 224-255.

18. Berka, M. and Zimmermann C. (2011) Basel accord and financial intermediation: The impact of policy. Federal Reserve Bank of St. Louis. Working paper 2011042A. 
19. Demirgüc-Kunt, A. and Detragiache, E. (2011) Basel core principles and bank soundness: Does compliance matter? Journal of Financial Stability 7: 179-190. 